\title{
РАЗДЕЛЕНИЕ МЕТИЛОВЫХ ЭФИРОВ ВЫСШИХ ЖИРНЫХ КИСЛОТ МЕТОДОМ ПРЕПАРАТИВНОИ ГАЗОВОЙ ХРОМАТОГРАФИИ. I. ПРЕДВАРИТЕЛЬНЫЕ ОПЫТЫ
}

T. SAKS, A. IVANOV, N. SAMEL. KORGEMATE RASVHAPETE METUOLESTRITE LAHUTAMINE PREPARATIIVSE GAASIKROMATOGRAAFIA MEETODIL. I. EELKATSED

T. SAKS, A. IVANOV, N. SAMEL. PREPARATIVE PURIFICATION OF METHYL ESTERS OF HIGHER FATTY ACIDS BY GAS CHROMATOGRAPHY. I. PRELIMINARY EXPERIMENTS

Для препаративного разделения жирных кислот в основном применяется жидкостная хроматография [']. Такой процесс достаточно трудоемок и связан с применением больших количеств растворителей, из которых чистая кислота получается путем концентрирования на ротационном испарителе. Поэтому метод препаративной газовой хроматографии (ПГХ) для выделения нескольких миллилитров веществ более перспек-

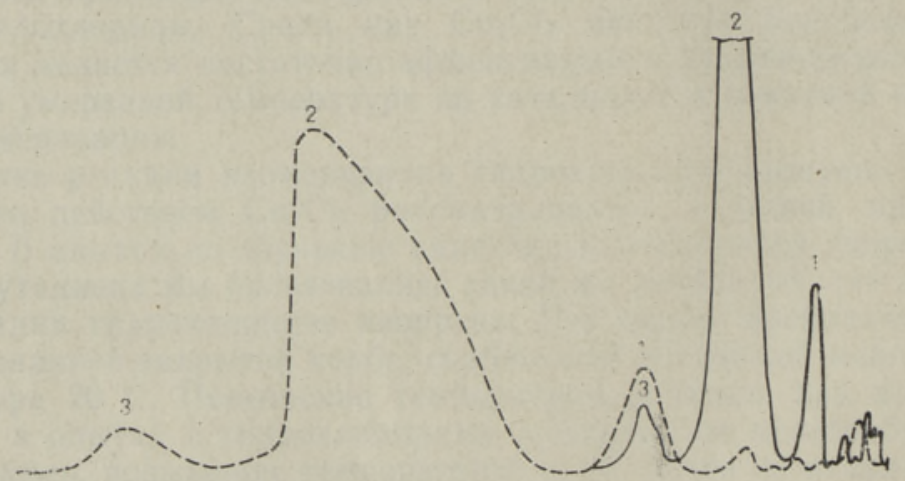

Рис. 1. Препаративные хроматограммы метилового эфира оленновой кислоты (пик 2) в вакуумном режиме (сплошная линия) и в обычном режиме (пунктир) при равных скоростях газа-носителя.

тивен. Однако разделение ПГХ жирных кислот является крайне трудной проблемой не только из-за выбора селективной жидкой фазы, но и в связи с размыванием пиков, появлением аэрозолей при конденсации, разложением веществ после колонки и конденсации веществ до лову- 
Рис. 2. Препаративные хроматограммы метилового эфира оленновой кислоты (пик 2) в вакуумном режиме (сплошная линия) и в обычном режиме (пунктир) при равных временах выхода.

шек. Основной причиной этих явлений в данном случае оказывается высокая температура кипения метиловых эфиров жирных кислот. Для уменьшения влияния этих факторов были проведены опыты в разреженной атмосфере газа-носителя. С этой целью к хроматографу Хром-31-KZ подключали вакуумный насос ВН-461 M, сразу после ловушек. Сравнительные опыты обычного и вакуумного режимов проводили в следующих условиях: длина колонки - 2,5 м; внутренний диаметр - 12 мм; твердый носитель - хроматон- $N$ - $A W \quad(0,4-$ 0,315 мм); жидкая фаза - гептафениловый эфир (10\% от веса носителя); детектор -

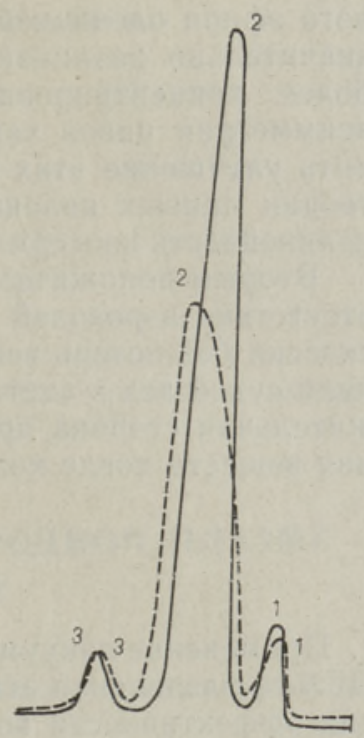
катарометр; температура: колонки $275^{\circ} \mathrm{C}$, катарометра $285^{\circ}$, испарителя $350^{\circ}$, распределителя $285^{\circ}$; вводимая доза - 300 мкл; давление газаносителя Не на выходе из колонки: а) в вакуумном режиме $<5$ мм pт. $c T$., в обычном режиме - атмосферное.

При проведении предварительных опытов был использован в качестве вещества этиловый эфир олеиновой кислоты $\mathrm{C}_{17} \mathrm{H}_{33}-\mathrm{COOC}_{2} \mathrm{H}_{5}$ с температурой кипения $340^{\circ}$ при 760 м. рт. $с т$., который содержит два основных пика неизвестных примесей (рис. 1 и 2).

На рис. 1 показаны препаративные хроматограммы обоих вариантов при одинаковых скоростях газа-носителя. Хорошо видно, что применение вакуума намного сокрашает время выхода веществ. Но более важными для данного исследования явились результаты проведения разделения при равных временах выхода веществ (при этом скорость газаносителя в разреженной атмосфере намного меньше, чем в обычном режиме). Приведенные на рис. 2 препаративные хроматограммы характеризуют такой случай. Опыты показали, что хроматографические характеристики (фактор асимметричности, высота эквивалентной теоретической тарелки и т. д.) для пиков 1 и 3 (содержание которых, соответственно, $2,5 \%$ и 4,5\%) практически идентичны, в то время, как такие же показатели для этило-

Рис. 3. Зависимость уровня улавливания этилового эфира олеиновой кислоты от времени удерживания в обычном режиме при температуре охлаждения $0{ }^{\circ} \mathrm{C}(\mathbf{\Delta})$ и в вакуумном режиме при температуре охлаждения $0{ }^{\circ} \mathrm{C}$ () и и $-60^{\circ} \mathrm{C}$ (圆).

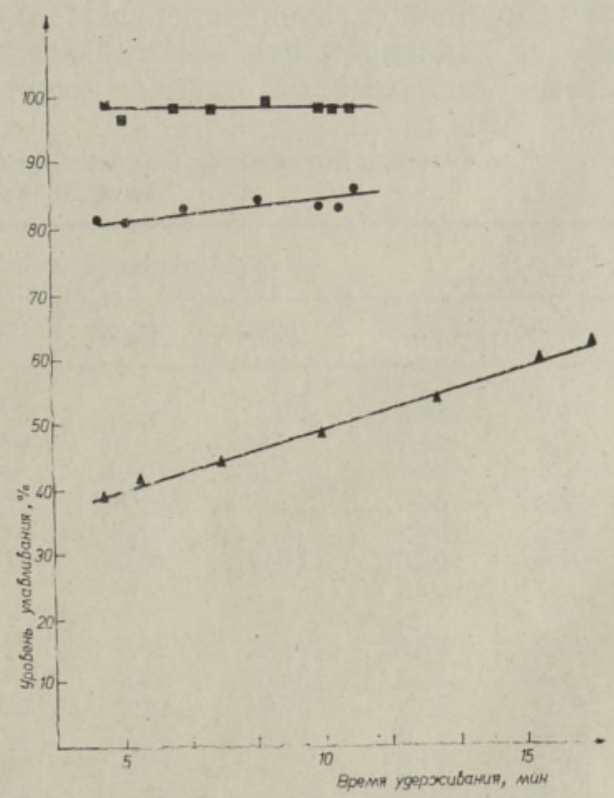


вого эфира олеиновой кислоты (рис. 1 и 2 , пик 1 с содержанием $88 \%$ ) значительно различаются в обоих случаях. Фронт кислоты в вакууме более концентрирован, и пик более симметричен. Расширение и асимметрия пиков характерны, в первую очередь, для ПГХ, но объяснить улучшение этих факторов в вакууме трудно из-за несовершенства теории данных явлений. Вероятно, что в данном случае уменьшается нелинейность изотермы адсорбции.

Вторым положительным эффектом при применении вакуума является отсутствие аэрозолей при конденсации. Конденсация происходит практически без потерь вещества (рис. 3). Для охлаждения ловушек применяли сухой лед в ацетоне с температурой $-60^{\circ}$. И, наконец, третья положительная сторона применения вакуума - полное отсутствие разложения веществ после колонки и отсутствие конденсации до ловушек.

\section{Выводы}

1. Применение вакуума позволило заметно повысить производительность ПГХ-го разделения этилового эфира олеиновой кислоты за счет улучшения эффективности колонки и более полного улавливания веществ из газового потока.

2. Подключение вакуумного насоса к хроматографу Хром-31-KZ не требует никаких перестроек и осуществляется просто.

\section{ЛИТЕ Р А Т У Р А}

1. S te in, R. A., Slaw s o n, V. Investigations of adsorption of unsaturated fatty acid methyl esters on silicic acid-silver nitrate. - Analyt. Chem., 1968, v. 40, N 13, p. $2017-2020$.

\section{Ннститут химии}

Академии наук Эстонской ССР
Поступила в редакцию 24/XI 1977 